Hans Kuhn 



\author{
Hans Kuhn
}

\title{
Kleine Schriften
}

Aufsätze und Rezensionen aus den Gebieten der germanischen und nordischen Sprach-, Literatur- und Kulturgeschichte

Vierter Band

Aufsätze

aus den Jahren 1968-1976

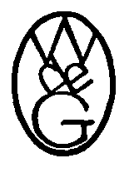

Walter de Gruyter $\cdot$ Berlin $\cdot$ New York

1978 
Kleinere Schriften zur Literatur- und Geistesgeschichte

Herausgegeben von

Dietrich Hofmann

in Zusammenarbeit mit

Wolfgang Lange und Klaus von See

CIP-Kurztitelaufnabme der Deutschen Bibliothek

\section{Kuhn, Hans}

[Sammlung]

Kleine Schriften : Aufsätze u. Rezensionen aus d. Gebieten d. german. u. nord. Sprach-, Literatur- u. Kulturgeschichte / [hrsg. von Dietrich Hofmann in Zusammenarbeit mit Wolfgang Lange u. Klaus von See]. - Berlin, New York : de Gruyter. Bd. 4. Aufsätze aus den Jahren 1968 - 1976. - 1. Aufl. - 1978.

(Kleinere Schriften zur Literatur- und Geistesgeschichte) ISBN 3-11-007077-4

(C)

Copyright 1978 by Walter de Gruyter \& Co., vormals G. J. Göschen'sche Verlagshandlung - J.Guttentag, Verlagsbuchhandlung - Georg Reimer - Karl J. Trübner - Veit \& Comp. - Printed in Germany - Alle Rechte des Nachdrudss, einschließlich des Rechtes der Herstellung von Photokopien und Mikrofilmen, vorbehalten.

Satz und Drudk: Saladrudk, Berlin

Bindearbeiten: Lüderitz \& Bauer, Berlin 